\title{
Notes on Some Copepoda from Plymouth.
}

\author{
By
}

\author{
Robert Gurney.
}

With 4 Figures in the Text.

\section{Tisbe elongata A. Scott. Harpacticid inhabiting the Gill Chamber OF THE LOBSTER.}

WHEN examining the gills of a lobster for specimens of Nicothoe large numbers of copepods were found which, colourless and slender in form, had the sluggish and rather aimless movements which one would expect from a commensal removed from its natural habitat. It was somewhat of a surprise to find that they all belonged to a species already described -Tisbe elongata A. Scott. Scott obtained a few specimens from mud collected on mussel beds between Heysham and Morecambe. It appears, then, that we have here a species which is capable of free life, but its abundance, in all stages of growth, in the gill chamber of a lobster, proves that it is also to be considered a semi-parasite.

The occurrence is of some interest, as examples of parasitism are rare among Harpacticids. The closest parallel is the record of Kröyer of Machairopus hippolytes (Kröyer) in the gill chamber of Spirontocaris groenlandica Fabr. Hansen* supposed that this occurrence was accidental; but it is probable that this is also a case of semi-parasitism.

Aurivillius has recorded the finding of Tisbe furcata in the Ascidian Molgula ampulloides, but this was no doubt simply accidental, as $T$. furcata is a ubiquitous littoral species. The only Harpacticid actually becoming a fixed and more or less degenerate parasite is also a member of the Tisbidæ-Cholidya polypi Farran parasitic on Octopus. Other more or less parasitic species are :-

Balanophilus unisetis Aurivillius, on Whales. Sunaristes paguri Hesse, in shells of Hermit Crabs. Cancrincola jamaicensis Wilson, on gills of the crab Cardisoma. Cancrincola wilsoni Pearse, on gills of the crab Sesarma. Nitocrameira bdellurce Liddell, on gills of Limulus. Nitocra divaricata Chappuis, on gills of Potamobius. Tisbe wilsoni Seiwell, in the Ascidian Amaroucium. 


\section{Larval Stages of Misophria pallida Boeck.}

The systematic position of Misophria is still a matter of complete uncertainty, and it was to be expected that its nauplius, if it could be found, might throw light on the subject. At Plymouth $M$. pallida is extremely difficult to obtain, but can be found by diligent search of dredgings from the Sound. During two visits, however, none were to be found with eggs, and it was only on the third attempt, in July 1932, that egg-bearing females were taken and the eggs successfully hatched.

The female bears $2-4$ large eggs, loosely attached to the genital somite, but not, apparently, enclosed in a definite egg-sac, and the eggs seem

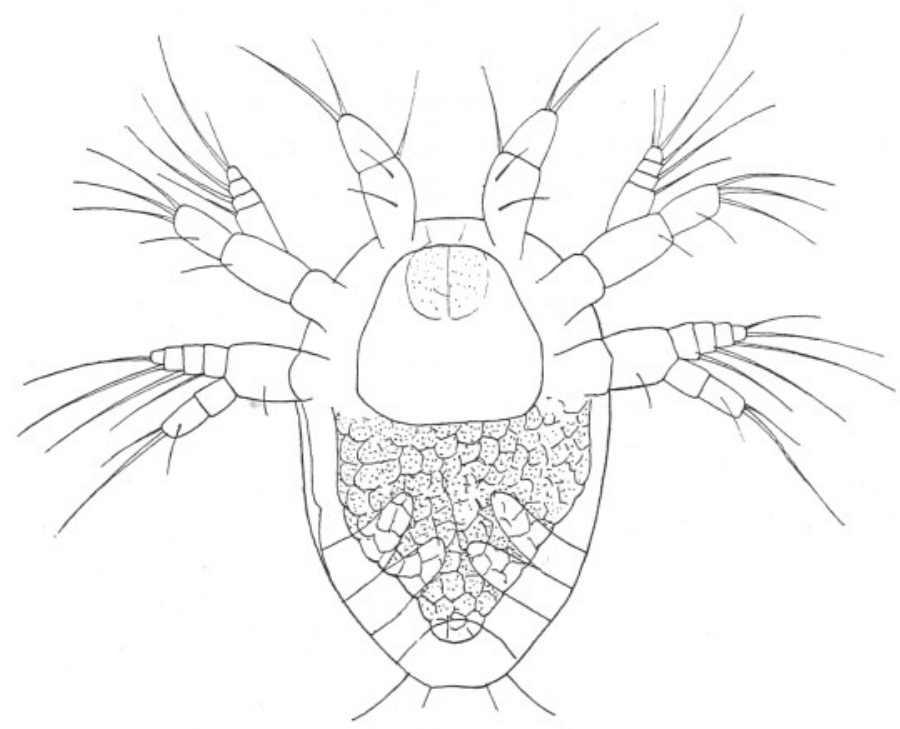

FIg. 1.-Nauplius of Misophria pallida.

to be carried for a considerable time before hatching. Unfortunately the nauplius, after all, provides no definite evidence for the systematic position of the adult. It is without eye or mouth, the body filled with yellow yolk, and the appendages naturally without any masticatory processes (Fig. 1). The antennæ and mandibles are large, with 4-segmented exopods, and beneath the cuticle can be seen rudiments of legs 1 and 2 . Within about a day it moults to the 1st copepodid stage which has the same habit as the adult of gliding movement on the bottom. The appendages, though not fully developed, are quite of the adult plan (Fig. 2).

What is of interest in this life-history is the almost complete cutting out of the nauplius stages. No Calanoid and no Harpacticid is known 
with a yolk-filled egg of this type and a non-feeding nauplius, a point which may be regarded as some evidence against relation to either of these groups. Among the Cyclopoida also nothing of the kind is known, except

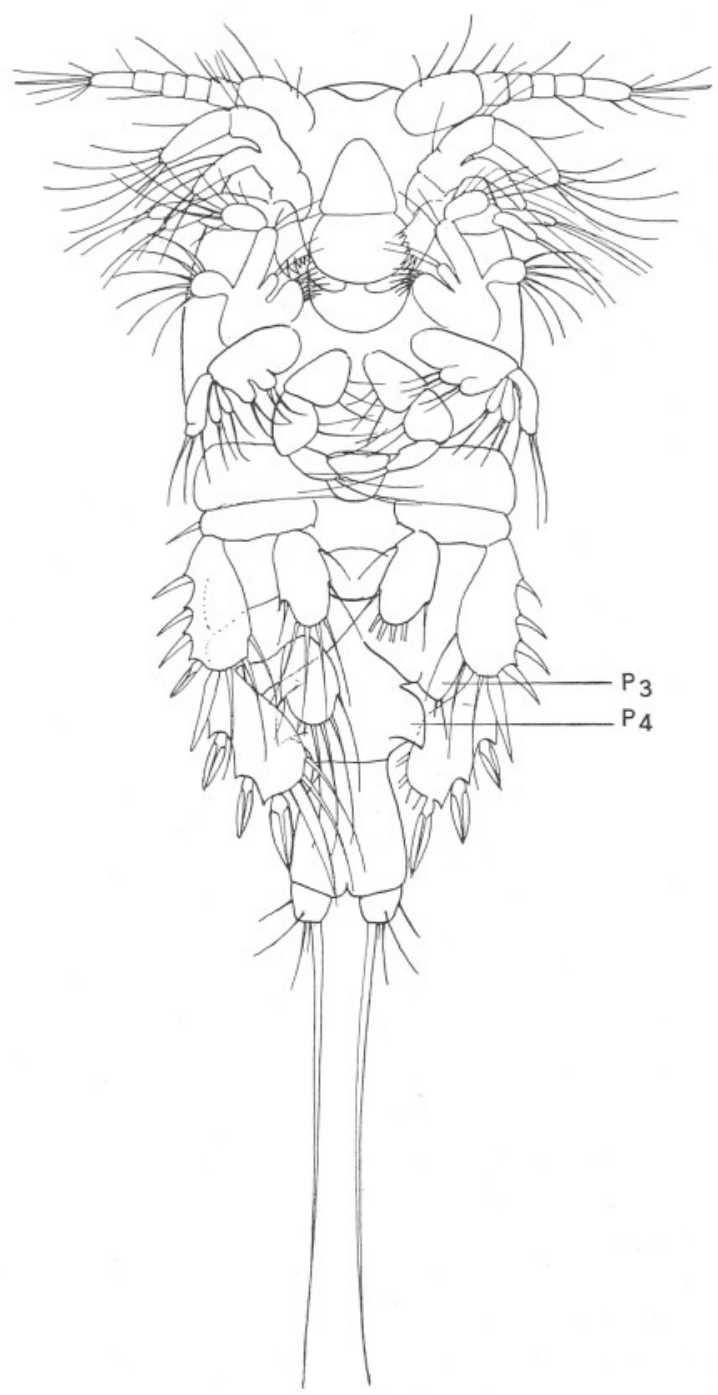

Fıg. 2.-Misophria pallida, first Copepodid stage.

among the semi-parasites such as the Ascomyzontidæ, and there cannot be any question of any relation to them. The nauplius may be said to resemble much more closely the Cyclopoid type than that of the Calanoids, and to be quite unlike that of such Harpacticids as are known, and to 
this very small extent relation to the Cyclopoida is suggested. The copepodid provides no useful evidence. The same plan in stage I is universal among Copepods, and the appendages already have the characters of the adult. If any conclusion can be drawn from the meagre facts, it seems to be that, in its larval history, as in its adult structure, Misophria holds an isolated place, which can best be expressed by regarding it as the type of a separate Order Misophrioida.

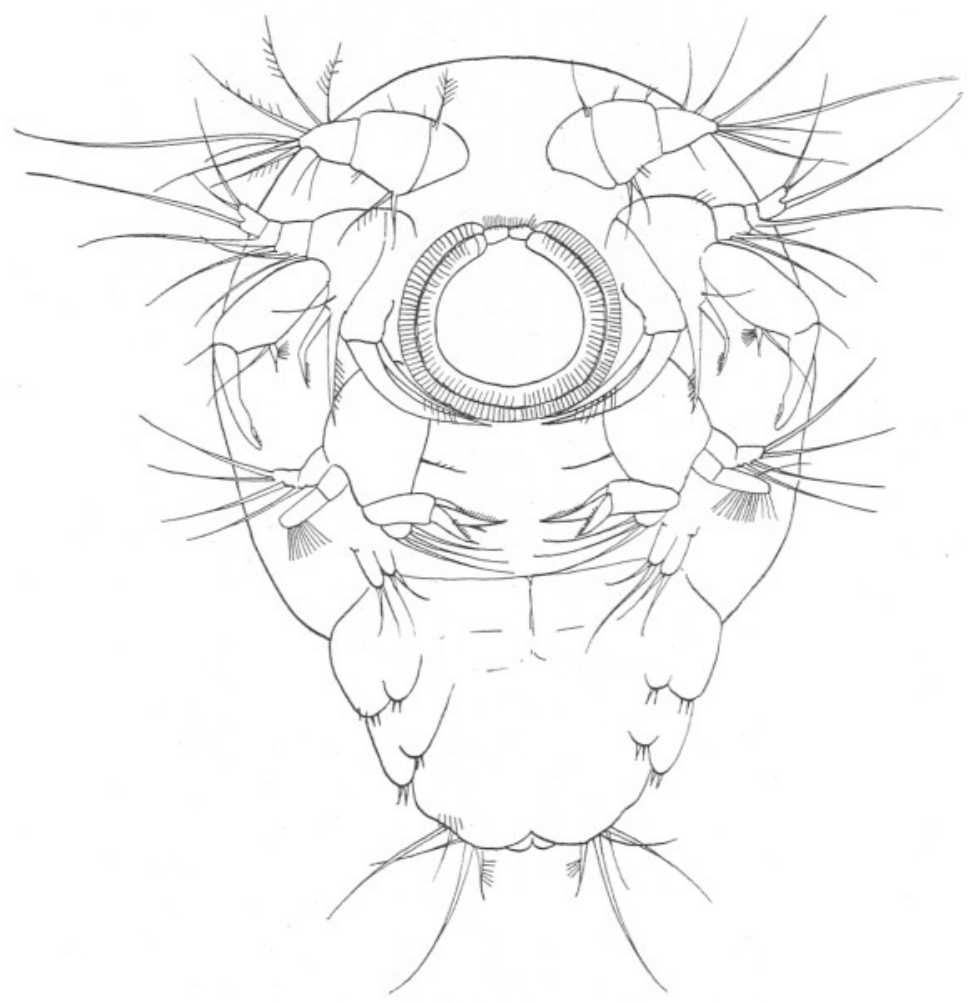

Fig. 3.-Nauplius of Psamathe longicauda.

\section{The Nauplius of Psamathe longicauda Philippi.}

Among a number of littoral Harpacticids handed over to me by Mr. John Colman were some nauplii of Psamathe longicauda which proved to have a structure of unusual interest (Fig. 3). This nauplius has already been described by Brian,* but without drawing special attention to the particular point of importance, which is the modification of the whole of the upper lip into a sucker. The upper lip is a hollowed circular dise the margins of which are strengthened by radial chitinous rods and fringed

\footnotetext{
* I copepodi Harpacticoidi del Golfo di Genova, 1921, p. 25.
} 
with very delicate hairs (Fig. 4). Anteriorly there is a gap in the dise which is closed by a pair of hairy pads. This sucking dise persists through the nauplius stages, but is lost at the moult to the copepodid, in which the upper lip is not modified. So far as I know a sucker of this kind is quite unknown in all other Harpacticids. In the closely allied Aspidiscus littoralis there is nothing of the kind, but in this case the margin of the dorsal shield has a delicate hyaline membrane which may serve to convert the whole body into a sort of sucker. On the other hand, suckers of strikingly similar form are found on the maxillæ of the Branchiura, which are not Copepods at all, on the anterior margin of the head in some

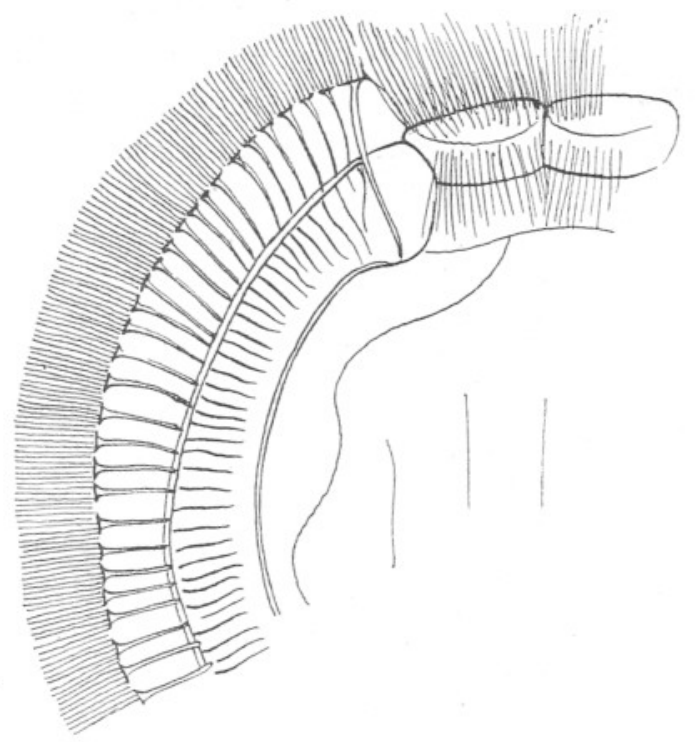

Fig. 4.-Structure of the Sucker of Psamathe longicauda.

Caligidæ, and in a number of parasitic forms at the apex of the mouth cone. In this last case, however, the sucking disc is largely, or wholly, the product of the modified lower lip, and the mandibles are enclosed in the mouth cone. The closest parallel to the disc of Psamathe seems to be found in Eunicicola. According to the figures given by Sars of $E$. clausi the disc is here, as in Psamathe, entirely formed by the upper lip, and the mandible, if it exists, is behind it. It is therefore simply an organ of adhesion and not, as in Lernæopods, for example, a sucking dise for feeding purposes.

\section{The Nauplius of Notodelphys.}

In his description of the nauplii of Notodelphys agilis and Doropygus porcicauda* Mr. Peter Gray draws special attention to the absence of an

* Journ. Mar. Biol. Assoc., xviii, p. 519, 1933. 
endopod from the mandible, which he claims to be otherwise unknown among nauplii. This is not altogether true, since an uniramous mandible is found in certain Branchiopod nauplii, but it is a remarkable feature in a Copepod. On the other hand Canu, in 1892,* gave excellent figures of the nauplii of Notodelphys agilis and of Doropygus gibber, and in both cases showed a small endopod on the mandible. I have myself seen the nauplius of $N$. allmani, and in this species (which is also figured by Canu) the endopod is quite distinct. A difference between the two species $D$. porcicauda and $D$. gibber in this respect is not impossible, but seems most unlikely, in view of the fact that an endopod is present in all the nauplii of Notodelphyids described by Canu-Bonnierella longipes, Doroixys uncinata, Enterocola fulgens, Aplostoma brevicauda, besides those mentioned above.

* Trav. Lab. Zool. Wimereux, vi, 1892. 